\title{
PENGARUH PENERAPAN GOOD CORPORATE GOVERNANCE TERHADAP PROFITABILITAS PADA BANK UMUM SYARIAH PERIODE 2014-2018
}

\section{THE IMPACT OF GOOD CORPORATE GOVERNANCE APPLICATION FOR PROFITABILITY OF SHARIA BANKS ON 2014-2018}

\author{
Putri Alma Gholy ${ }^{1}$; Prameswara Samofa Nadya ${ }^{2 a}$ \\ 1Program Studi S1 Ekonomi Syariah IKPIA Perbanas, Jl. Perbanas, Karet Kuningan - Jakarta Selatan \\ ${ }^{2}$ Program Studi S1 Ekonomi Syariah IKPIA Perbanas, Jl. Perbanas, Karet Kuningan - Jakarta Selatan \\ aKorespondensi: Prameswara Samofa Nadya, e-mail: prameswara.samofa@perbanas.id
}

\begin{abstract}
The application of Good Corporate Governance (GCG) is the way to control a corporate professionally and transparently to reach goals agreed by both shareholders and stakeholders. So, it is expected Islamic banks can perform with a good quality and consistently implementing GCG mechanism along with increasing profits. Therefore, this research focused on appraising profitability increasing with Return on Asset (ROA) and Return on Equity (ROE) as indicator, together with appraising GCG with self assessment reports based on 11 criteria of composite rate valuation. This research used quantitative method from GCG reports and annual report of Islamic Banks from 2014-2018 period, as secondary data. The result was GCG as independent variable positively and significantly effecting ROA and ROE.
\end{abstract}

Key words: GCG, composite rate, ROA, ROE, Islamic Banks

\begin{abstract}
ABSTRAK
Penerapan Good Corporate Governance (GCG) merupakan suatu cara untuk mengendalikan perusahaan secara profesional dan transparan untuk mencapai tujuan bersama antara pemegang saham dan pengelola. Oleh karena itu, diharapkan Bank Umum Syariah dapat memberikan kualitas yang baik dan konsisten dalam menerapkan mekanisme GCG serta peningkatan profitabilitas. Untuk menilai peningkatan profitabilitas dalam penelitian ini dengan indikator rasio Return on Asset (ROA) dan Return on Equity (ROE), dan untuk menilai kualitas penerapan GCG dapat dilihat dari laporan Self Assessment setiap bank dengan nilai komposit dari 11 kriteria yang telah ditentukan. Penelitian ini menggunakan metode kuantitatif dengan data sekunder dari laporan GCG dan laporan keuangan tahunan periode 2014-2018. Didapatkan 11 Bank Umum Syariah yang sesuai dengan kriteria. Hasil penelitian menunjukkan bahwa variabel independen GCG berpengaruh secara positif dan signifikan terhadap ROA dan ROE.

Kata kunci: GCG, peringkat komposit, ROA, ROE, Bank Umum Syariah
\end{abstract}

Putri Alma Gholy. 2020. Pengaruh Penerapan Good Corporate Governance Terhadap Profitabilitas Pada Bank Umum Syariah. Jurnal Nisbah 6 (2): 108-115.

\begin{abstract}
PENDAHULUAN
Dalam melakukan kegiatan operasionalnya, Bank Syariah memiliki tujuan mendapatkan laba atau keuntungan untuk menjamin kelangsungan hidup perusahaan. Profitabilitas merupakan salah satu tolok ukur dalam kinerja keuangan suatu bank.
\end{abstract}

Dalam rangka meningkatkan kinerja perusahaan, baik operasional maupun keuangan, agar tercipta proses pengambilan keputusan yang lebih baik, meningkatkan efisiensi operasional perusahaan, serta meningkatkan pelayanan yang lebih baik, Bank Syariah dituntut untuk menjalankan kegiatan 
operasionalnya dengan berpedoman pada prinsip-prinsip tata Kelola perusahaan yang baik atau Good Corporate Governance (GCG).

GCG menciptakan sistem pengendalian dan keseimbangan untuk mencegah penyalahgunaan dari sumber daya dan tetap mendorong terjadinya pertumbuhan perusahaan. Dalam penerapan GCG, Bank Syariah harus mematuhi prinsip Syariah (sharia compliance) dalam kegiatannya. Penerapan GCG secara konsisten dapat memperkuat posisi daya saing perusahaan, memaksimalkan nilai perusahaan, mengelola sumber daya dan risiko secara lebih efisien dan efektif, sehingga tercipta kepercayaan yang kokoh antara pemegang saham (shareholders) dan pemangku kepentingan atau pengelola (stakeholders), sehingga berdampak baik pada perkembangan industri perbankan Syariah. Ketidaksesuaian tata Kelola dalam bank Syariah dapat berpotensi buruk dan mengalami risiko finansial, bahkan risiko reputasi.

Dalam meningkatkan dan memperbaiki kualitas penerapan GCG dalam Bank Umum Syariah maka Bank diwajibkan melaporkan secara berkala self assessment sesuai Surat Edaran No. 12/13/DPbS tahun 2010. Penilaian atas pelaksanaan GCG bagi BUS dilakukan terhadap 11 faktor dengan bobot tertentu.

Adapun kriteria pemeringkatan disusun antara peringkat 1 hingga peringkat 5 , di mana nilai terbaik ada pada peringkat 1, yaitu bahwa hasil analisis self assessment menunjukkan bahwa pelaksanaan GCG Bank sangat sesuai dengan kriteria/indikator dan terendah ada pada peringkat 5, yaitu bahwa hasil analisis self assessment menunjukkan bahwa pelaksanaan GCG Bank tidak sesuai dengan kriteria/indikator.

Berdasarkan penelitian sebelumnya, GCG berpengaruh positif terhadap kinerja keuangan (ROA) pada Bank Umum Syariah (Junaedi: 2017, Himawan: 2017), penerapan GCG terhadap ROE berpengaruh positif dan signifikan (Desiana, Mawardi, Gustiana: 2016, Hapsari: 2018), serta GCG berpengaruh positif dan signifikan baik terhadap ROA maupun ROE. (Tjondro \& Wilopo: 2011, Prasojo: 2015).

Untuk itu, permasalahan penelitian ini adalah: 1) Bagaimana pengaruh penerapan GCG terhadap ROA sebagai rasio profitabilitas pada periode 20142018; 2) Bagaimana pengaruh penerapan GCG terhadap ROE sebagai rasio profitabilitas pada periode 2014-2018?

\section{MATERI DAN METODE}

Penerapan GCG diharapkan dapat mengatasi masalah ketidakseimbangan informasi pada perusahaan yang dapat ditandai, baik oleh adverse selection maupun pada moral hazard. GCG merupakan konsep tata cara Kelola perusahaan yang sehat, yang mana konsep ini diharapkan dapat melindungi pemegang saham dan kreditur agar dapat memperoleh kembali investasinya. Terdapat 2 hal yang ditekankan dalam konsep GCG, yaitu pentingnya hak pemegang saham untuk memperoleh informasi dengan benar (akurat) dan tepat pada waktunya, serta kewajiban perusahaan untuk melakukan pengungkapan (disclosure) secara akurat, tepat waktu dan transparan terhadap semua informasi kinerja perusahaan, kepemilikan dan pemangku kepentingan. (Khairandy \& Malik, 2007)

Terdapat 5 asas yang diperlukan oleh perusahaan untuk mencapai kesinambungan perusahaan dengan memperhatikan pemangku kepentingan, yaitu transparansi, akuntabilitas, responsibilitas, independensi serta kewajaran dan kesetaraan. Asas tersebut sesuai dengan PBI Nomor 84 Tahun 2006 tentang Pelaksanaan GCG Bagi Bank Umum, di mana Bank wajib menerapkan prinsip-prinsip sesuai 5 asas tersebut.

Penerapan GCG diharapkan mampu meningkatkan nilai tambah bagi para pemangku kepentingan melalui tujuan- 
tujuan, yaitu meningkatkan efisiensi, efektifitas serta kesinambungan organisasi, menciptakan legitimasi organisasi, serta mengakui dan melindungi hak dan kewajiban shareholders dan stakeholders (Kusmayadi, Rudiana \& Badruzaman, 2015).

Dalam kacamata Islam, GCG harus mengacu pada prinsip-prinsip tauhid, taqwa dan ridha, keseimbangan dan keadilan, serta kemaslahatan (Muqarabin, 2008). Dalam PBI No. 11 Tahun 2009, untuk menjalankan 5 asas GCG, Bank Syariah wajib berpedoman kepada peraturan yang berlaku serta sesuai dengan prinsip Syariah. Peran Dewan Pengawas Syariah (DPS) adalah menjaga kepatuhan Syariah, sehingga dapat dipastikan bahwa prinsip-prinsip Syariah telah terpenuhi pada pedoman operasional dan produk perbankan yang dikeluarkan.

Berdasarkan PBI Nomor 11 Tahun 2009, ditunjang oleh Surat Edaran BI Nomor 12/13/DPbS/2010 perihal Pelaksanaan GCG Bagi Bank Umum Syariah dan Unit Usaha Syariah, penilaian atas pelaksanaan GCG dilakukan terhadap 11 faktor yang masing-masing mempunyai bobot tertentu yang akan dipergunakan dalam perhitungan self assessment, yaitu: 1) Pelaksanaan tugas dan tanggung jawab Dewan Komisaris (bobot 12,50\%); 2) Pelaksanaan tugas dan tanggung jawab Direksi (bobot 17,50\%); 3) Kelengkapan dan pelaksanaan tugas Komite (bobot 10,00\%); 4) Pelaksanaan tugas dan tanggung jawab Dewan Pengawas Syariah (bobot 10,00\%); 5) Pelaksanaan prinsip Syariah dalam kegiatan penghimpunan dana dan penyaluran dana serta pelayanan jasa (bobot 5,00\%); 6) Penanganan benturan kepentingan (bobot 10,00\%); 7) Penerapan fungsi kepatuhan bank (bobot 5,00\%); 8) Penerapan fungsi audit intern (bobot 5,00\%); 9) Penerapan fungsi audit ekstern (bobot 5,00\%); 10) Batas Maksimum Penyaluran Dana (bobot 5,00\%); serta 11) Transparansi kondisi keuangan dan non keuangan BUS, laporan pelaksanaan GCG serta pelaporan internal (bobot 15,00\%).

PBI Nomor 11 Tahun 2009 dan Surat Edaran BI Nomor 12/13/DPbS/2010 juga mengatur tentang peringkat yang diberikan setelah BUS melakukan self assessment dengan cara membandingkan pemeuhan setiap kriteria atau indikator dengan kondisi Bank berdasarkan data dan informasi yang relevan, yaitu: 1) Peringkat 1: hasil analisis self assessment menunjukkan bahwa pelaksanaan GCG Bank sangat sesuai dengan kriteria/indikator; 2) Peringkat 2: hasil analisis self assessment menunjukkan bahwa pelaksanaan GCG Bank sesuai dengan kriteria/indikator; 3) Peringkat 3: hasil analisis self assessment menunjukkan bahwa pelaksanaan GCG Bank cukup sesuai dengan kriteria/indikator; 4) Peringkat 4: hasil analisis self assessment menunjukkan bahwa pelaksanaan GCG Bank kurang sesuai dengan kriteria/indikator; serta 5) Peringkat 5: hasil analisis self assessment menunjukkan bahwa pelaksanaan GCG Bank tidak sesuai dengan kriteria/indikator. Peringkatperingkat ini ditentukan untuk setiap faktor dan dikalikan dengan bobot yang melekat pada faktor tersebut.

Untuk mendapatkan nilai komposit, Bank menjumlahkan nilai dari seluruh faktor, sehingga didapatkan predikat komposit sebagai berikut: 1) Nilai komposit <1,5 diberi predikat 'Sangat Baik'; 2) Nilai komposit 1,5 hingga $<2,5$ diberi predikat 'Baik'; 3) Nilai komposit 2,5 hingga $<3,5$ diberi predikat 'Cukup Baik'; 4) Nilai komposit 3,5 hingga $<4,5$ diberi predikat 'Kurang Baik'; dan 5) Nilai komposit 4,5 hingga 5 diberi predikat 'Tidak Baik'.

Selain Laporan GCG, BUS juga wajib melaporkan kinerja keuangan dalam bentuk Laporan Keuangan. Pengukuran kinerja keuangan dalam perusahaan adalah hal yang penting di mana dengan adanya penilaian tersebut manajer dapat memikirkan dan menentukan struktur keuangan di masa mendatang yang lebih 
baik dan efisien. Beberapa hal yang diukur dalam laporan keuangan adalah 1) Likuiditas, yang merupakan ukuran kemapuan bank dalam memenuhi kewajiban jangka pendeknya; 2) Profitabilitas, yaitu tingkat efektivitas yang dicapai melalui usaha operasional bank yang digunakan untuk mengukur kemampuan perusahaan dalam memperoleh laba atau keuntungan; serta 3) Solvabilitas, yaitu pengukuran perbandingan dana yang disediakan oleh pemilik dengan dana yang dipinjam dari kreditur perusahaan.

Dari semua hal tersebut, profitabilitas merupakan indikator yang paling tepat dalam pengukuran kinerja perusahaan. Semakin tinggi profitabilitasnya maka semakin bagus kinerja keuangan perusahaan. Beberapa rasio yang dapat digunakan dalam profitabilitas adalah Return on Asset (ROA) dan Return on Equity (ROE). ROA didapatkan dengan cara membandingkan laba bersih dengan total aset perusahaan, yang merupakan tolok ukur keberhasilan manajemen perusahaan atas aset yang dimiliki (Fakhruddin, 2008). ROE didapatkan dengan cara membandingkan laba bersih dengan total ekuitas perusahaan, yang merupakan tolok ukur efektivitas penggunaan modal untuk menghasilkan laba (Fakhruddin, 2008).

Berdasarkan penelitian yang telah dilakukan oleh Yantiningsih, Islahuddin \& Musnadi (2016) terhadap Perbankan Syariah tahun 2010-2014, GCG berpengaruh positif dan signifikan terhadap profitabilitas ROA dan ROE. hal ini didukung oleh hasil penelitian Pratiwi (2016), Tjondro \& Wilopo (2011), Prasojo (2015). Penelitian Junaedi (2017) menyatakan bahwa GCG berpengaruh positif terhadap kinerja keuangan yang diproksikan dengan ROA, demikian pula hasil yang didapatkan oleh Himawan (2017), Wulandari (2019) serta Ferdyant, Anggraini ZR \& Takidah (2014), sedangkan Pudail, Fitriyani, Labib (2018) menemukan bahwa GCG berpengaruh terhadap ROA, namun tidak terhadap ROE. penelitian Desiana, Mawardi \& Gustina (2016) menyebutkan bahwa GCG berpengaruh positif dan signifikan terhadap ROE, demikian pula menurut penelitian Hapsari (2018).

Mengacu pada teori dan temuantemuan pada penelitian sebelumnya, penelitian ini disusun dengan cara membandingkan pengaruh GCG terhadap ROA dan ROE yang merupakan representasi dari profitabilitas pada BUS.

Penelitian dilakukan dengan menganalisis data sekunder berupa nilai komposit self assessment untuk mendapatkan data GCG, serta laporan keuangan untuk mendapatkan data ROA dan ROE pada 11 BUS periode tahun 20142018, yaitu Bank BCA Syariah, Bank BNI Syariah, Bank BRI Syariah, Bank Mega Syariah, Bank Muamalat Indonesia, Bank Panin Dubai Syariah, Bank Syariah Bukopin, Bank Syariah Mandiri, Bank Victoria Syariah, Maybank Syariah dan Bank Jabar Banten Syariah, untuk kemudian melakukan analisis regresi data panel.

Tiga macam pengujian, yaitu uji chow, uji hausman dan uji lagrange multiplier dilakukan, masing-masing untuk menentukan model yang paling tepat antara fixed effect, common effect dan random effect. Uji asumsi klasik juga dilakukan untuk memastikan lineritas, otokorelasi, heteroskedastisitas dan normalitas data.

Analisis statistik deskriptif juga dilakukan untuk menganalisis data dalam rangka menggambarkan hasil penelitian atas variabel-variabel yang diteliti.

\section{HASIL DAN PEMBAHASAN}

Berdasarkan hasil pengolahan data statistik untuk melihat hubungan ROA dengan GCG, diperoleh persamaan regresi data panel yaitu:

$$
\mathrm{Y} 1=2,257675 \text { - 1,027758X + eit }
$$

yang berarti bahwa jika GCG selaku variabel X bernilai nol (0) maka ROA besarnya adalah 2,257675. Dan jika indeks 
komposit GCG mengalami penurunan sebesar 1 maka ROA, selaku salah satu indikator profitabiltas, akan mengalami peningkatan sebesar 1,027758 satuan, di mana penurunan angka indeks komposit justru merupakan indikator bahwa kinerja GCG bank semakin baik.

Untuk ROE, hasil regresi data panel menunjukkan persamaan:

$\mathrm{Y} 2=21,92625-12,90122 \mathrm{X}+$ eit

yang berarti bahwa jika GCG selaku variabel $X$ bernilai nol (0) maka ROE besarnya adalah 21,92625. Dan jika indeks komposit GCG mengalami penurunan sebesar 1 maka ROE, selaku salah satu indikator profitabiltas, akan mengalami peningkatan sebesar 12,90122 satuan.

Hasil Uji-T pada ROA dan ROE, keduanya menunjukkan bahwa $t$ hitung lebih besar daripada $t$ tabel yang berarti hipotesis diterima, atau GCG berpengaruh kepada ROA dan ROE. Demikian pula, hasil koefisien determinasi menunjukkan bahwa pengaruh penerapan GCG mempengaruhi $10,52 \%$ terhadap variasi variabel ROA dan penerapan GCG mempengaruhi $22,86 \%$ terhadap variasi variabel ROE.

Statistik deskriptif menunjukkan bahwa dari 11 BUS yang diteliti, nilai tertinggi GCG berdasarkan indeks peringkat komposit adalah 1 dan nilai terendah adalah 3 dengan variasi $\mathrm{ROE}$ yang lebih tinggi dari ROA, yang berarti bahwa tingkat pengembalian terhadap modal pada masing-masing BUS cenderung lebih fluktuatif daripada tingkat pengembalian terhadap aset bank.

Hasil penelitian ini membuktikan bahwa pada periode 2014 hingga 2018, penggunaan aset bank sehingga menghasilkan profitabilitas yang diharapkan lebih efektif daripada penggunaan modal bank untuk menghasilkan profitabilitas. Hasil penelitian juga menunjukkan bahwa penerapan GCG berpengaruh positif dan signifikan terhadap profitabilitas BUS.

Tata Kelola Perbankan Syariah yang baik diperlukan untuk mencapai kinerja optimal dari Bank Syariah, sehingga pada akhirnya dapat memaksimalisasikan laba Bank Syariah. Mekanisme GCG memiliki aturan untuk mengendalikan perusahaan secara professional dan transparan yang dapat membatasi munculnya penyalahgunaan aset perusahaan atas pengelolaan yang salah, sehingga menghasilkan budaya kerja yang sehat dalam perusahaan.

Penerapan mekanisme GCG dengan prinsip dasar yang terdapat pada PBI No. 11/33/PBI/2009 tentang Pelaksanaan GCG Bagi Bank Umum Syariah dan Unit Usaha Syariah, di mana transparansi dalam informasi dan pengambilan keputusan, akuntabilitas, responsibilitas dan profesionalitas, pada dasarnya telah terkandung dalam nilai-nilai Islam, yaitu adaalatun (keadilan), tawazun (keseimbangan), mas'uliyah (akuntabilitas), akhlaq (moral), shiddiq (kejujuran), amanah (dapat dipercaya), fathanah (cerdas), tabligh (komunikatif), hurriyah (bebas dan bertanggung jawab), ihsan (professional), wasathan (wajar), ghirah (semangat), idarah (pengelolaan), khilafah (kepemimpinan), aqidah (keimanan), ijabiyah (berpikiran positif), raqabah (pengawasan), qira'ah dan ishlah (terus berproses dalam perbaikan diri). Hal ini membuktikan bahwa nilai-nilai Syariah jauh lebih mendahului kelahiran prinsip-prinsip GCG.

Tuntunan Islam menghendaki adanya keseimbangan dalam membina hubungan, baik dengan Allah (hablumninallah) dan dengan sesama manusia (hablumminannaas). Dengan adanya keseimbangan tersebut, diharapkan hadir keberkahan dalam setiap pekerjaan dan amalan yang dilakukan, sesuai dengan perspektif bahwa segala pekerjaan dilakukan tidak sekedar mencari kegemilangan duniawi, tapi mencari falah, yaitu kemenangan dunia dan akhirat.

Apabila BUS selaku perusahaan menjaga tata kelolanya agar dapat berjalan dengan baik sesuai tuntunan, 
maka akan menjadikan kegiatan perusahaan berjalan secara optimal dan memberikan citra yang baik bagi Bank Syariah, sehingga mendapat respon positif, baik dari pemegang saham (shareholders), pemangku kepentingan (stakeholders), investor dan masyarakat umum.

Pelaksanaan penerapan GCG yang baik akan memberikan kinerja yang salah satunya tercermin dari profitabilitas. Hal ini sejalan dengan konsep keberkahan, di mana setiap amal baik akan mendapat balasan berupa pahala yang baik berupa surga dan tambahannya (QS 10:26)

\section{KESIMPULAN DAN IMPLIKASI}

Penelitian ini telah mampu membuktikan hipotesis bahwa terdapat pengaruh positif dan signifikan antara penerapan GCG terhadap profitabilitas, baik ROA maupun ROE pada 11 Bank Umum Syariah di Indonesia pada periode 2014-2018.

Hal ini sesuai dengan ekspektasi bahwa Bank Syariah sebagai sebuah entitas yang dibangun dan dikelola berdasarkan nilai-nilai Syariah mampu menjaga tata kelolanya dengan baik, sehingga mendapatkan keluaran yang baik pula dalam pelaksanaannya, di mana terlihat pada tingkat pengembalian atas aset (ROA), serta tingkat pengembalian atas modal (ROE) yang sejalan dengan performa GCG. Dengan kata lain, terdapat keberkahan atas upaya membangun tata Kelola perusahaan yang baik.

\section{DAFTAR PUSTAKA}

Amalia, Risky. 2014. Pengaruh Penerapan Good Corporate Governance Terhadap Profitabilitas Bank Umum Syariah di Indonesia tahun 20102013. Skripsi, UIN Syarif Hidayatullah.

Andrianto \& MA Firmansyah. 2019. Manajemen Bank Syariah (Implementasi Teori dan Praktek). Pasuruan: Qiara Media Partner.
Chapra, Umer. \& Habib Ahmed. 2008. Corporate Governance: Lembaga Keuangan Syariah. Jakarta: Bumi Aksara.

Desiana, L., Mawardi \& Gustiana. (2016). Pengaruh Good Corporate Governance Terhadap Profitabilitas (ROE) Pada Bank Umum Syariah di Indonesia Periode 2010-2015. A Research Journal On Islamic Finance Vol.2 No.2 hal 1-20.

Duli, Nikolaus. 2019. Metodologi Penelitian Kuantitatif: Beberapa Konsep Dasar Untuk Penulisan Skripsi \& Analisis Data Dengan SPSS. Yogyakarta: Deepublish

Ferdyant, F., ZR R. Anggraini, Erika Takidah. 2014. Pengaruh Kualitas Penerapan Good Corporate Governance dan Risiko Pembiayaan terhadap Profitabilitas Perbankan Syariah. Jurnal Dinamika Akuntansi Dan Bisnis. Vol 1 No 2 hal. 134-149.

Forum for Corporate Governance in Indonesia. 2012. Peranan Dewan Komisaris dan Komite Audit dalam pelaksanaan Good Corporate Governance. Jakarta: Citra Graha

Hapsari, Kirana. 2018. Pengaruh Good Corporate Governance Terhadap Kinerja Keuangan di Bank Umum Syariah Pada Tahun 2013-2015. Skripsi, IAIN Surakarta.

Himawan, Ibnu. 2017. Pengaruh Implementasi Good Corporate Governance Terhadap Profitabilitas Pada Bank Umum Syariah di Indonesia tahun 2011 - 2015. Skripsi, UIN Walisongo.

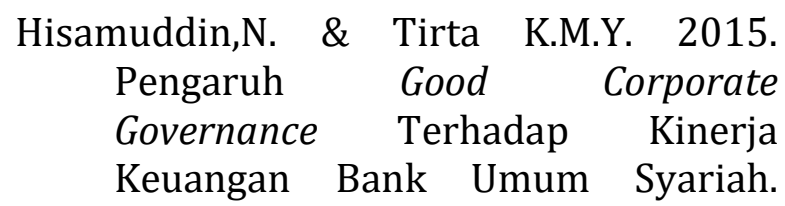


Jurnal Akuntansi Universitas Jember hal. 109-138.

Ihsan, Dwi N. 2016. Kualitas Penerapan Good Corporate Governance Pada Bank Umum Syariah di Indonesia Serta Pengaruhnya Pada Kinerja Keuangan. Jurnal Ekonomi Islam Vol.7 No.2 hal. 77-106.

Jumingan. 2011. Analisis Laporan Keuangan. Jakarta: PT. Bumi Aksara.

Junaedi, Juna. 2017. Analisis Pengaruh Good Corporate Governance dan Financial Leverage Terhadap Kinerja Keuangan Bank Umum Syariah Dengan Volume Pembiayaan Sebagai Variabel Moderasi. Jurnal Riset Keuangan dan Akuntansi Vol. 1 No.2

Khairandy,R \& Malik,C. 2007. Good Corporate Governance; Perkembangan Pemikiran dan Implementasinya di Indonesia dalam Perspektif Hukum. Yogyakarta: Kreasi Total Media.

Kusmayadi, D., Rudiana, D., Badruzaman, J. 2015. Good Corporate Governance. Tasikmalaya: LPPM Universitas Siliwangi.

Lestari, Rahma D. 2015. Pengaruh Good Corporate Governance Terhadap Kinerja Keuangan Pada Perbankan Syariah. Skripsi, Universitas Muhammadiyah Surakarta.

Mardani. 2012. Fiqh Ekonomi Syariah: Fiqh Muamalah, Jakarta: Kencana.

Margono, S. 2004. Metodologi Penelitian Pendidikan. Jakarta: PT Rineka Cipta.

Muchtar,B.,Rahmidani, R.,Siwi, M.K. 2016. Bank \& lembaga keuangan lainnya. Penerbit: Kencana.
Muqarabin, M. 2008. Fikih Tata Kelola Organisasi Laba: Sebuah Pengantar. Purwokerto: Universitas Muhammadiyah.

Nur'ainy, R., Nurcahyo, B., Kurniasih, S.A., Sugiharti, B. 2013. Implementation of Good Corporate Governance and Its Impact on Corporate Performance: The Mediation Role of Firm Size (Empirical Study from Indonesia)

Nurmalasari, Lina. 2018. Analisis Pengaruh Dana Pihak Ketiga (DPK), Non Perfoming Financing (NPF), Financing To Deposit Ratio (FDR), dan Biaya Operasional Terhadap Pendapatan Operasional (BOPO) Terhadap Profitabilitas Pada Bank Umum Syariah di Indonesia periode 2012-2016. Skripsi, Perbanas Institute.

Komite Nasional Kebijakan Governance. 2006. Pedoman Umum Good Corporate Governance Indonesia. www.knkg-indonesia.org

$$
\begin{array}{crr}
\text { Peraturan Bank } & \text { Indonesia } & \text { No. } \\
\text { 11/33/PBI/2009 } & \text { tanggal } & 7 \\
\text { Desember } & & 2009 \\
\text { https://www.bi.go.id/id/peraturan/ } \\
\text { perbankan/Pages/PBI_71209.aspx }
\end{array}
$$

Prabowo, Timothy. 2017. Analisis Pengaruh Good Corporate Governance Terhadap Kinerja Keuangan pada PT.BANK MANDIRI (PERSERO) TBK Periode 2011-2015. Skripsi, Perbanas Institute.

Prasojo. 2015. Pengaruh Penerapan Good Corporate Governance Terhadap Kinerja Keuangan Bank Syariah. Jurnal Dinamika Akuntansi dan Bisnis Vol.2 No.1 hal. 28-59.

Pratiwi, Angrum. 2016. Pengaruh Kualitas Penerapan Good Corporate Governance (GCG) terhadap Kinerja 
Keuangan pada Bank Umum Syariah di Indonesia (Periode 2010-2015). Jurnal Ekonomi dan Bisnis Islam. Vol.2 No.1, Hal 55-76.

Priyatno, Duwi. 2018. SPSS: Panduan Mudah Olah Data bagi Mahasiswa dan Umum. Yogyakarta: ANDI.

Pudail,M.,Fitriyani,Y.,Labib,A. 2018. Good Corporate Governance Dalam Meningkatkan Kinerja Keuangan Bank Syariah. Wahana Islamika: Jurnal Studi Keislaman Vol.4 No.1 hal.128-149.

Putra, Mirza K. 2018. Analisis Faktorfaktor Internal dan Eksternal yang Mempengaruhi Kinerja Bank Umum Syariah Tahun 2011-2016. Skripsi, Perbanas Institute.

Riandi, D. \& Siregar, H.S. 2011. Pengaruh Penerapan Good Corporate Governance terhadap ROA, NPM dan EPS pada Perusahaan yang Terdaftar di CGPI. Jurnal Ekonomi Volume 14 Nomor 3 hal 127-133.

Saputro, Andik S Dwi. 2010. Penguatan Shariah Governance Melalui Reformasi Akuntansi dalam Simposium Nasional Akuntansi XIII. Purwokerto: Universitas Jendral Soedirman.

Sugiyono. 2012. Metode Penelitian Kuantitatif Kualitatif dan R\&D. Bandung: Alfabeta.

Sugiyono. 2014. Metode Penelitian Manajemen. Bandung: Alfabeta.

Surat Edaran Bank Indonesia No. 12/13/DPbS tanggal 30 April 2010 https://www.bi.go.id/id/peraturan/pe rbankan/Pages/se_121310.aspx

Syukron, Ali. (2013). Dinamika Perkembangan Perbankan Syariah di
Indonesia. Jurnal ekonomi dan hukum islam Vol.3 No.2 hal. 28-53. 